\title{
Cross Spectral Analysis of CODAR-SeaSonde Echoes from Sea Surface and Ionosphere at Taiwan
}

\author{
Chien-Ya Wang, ${ }^{1}$ Ching-Lun $\mathrm{Su}^{2}{ }^{2}$ Kang-Hung Wu, ${ }^{2}$ and Yen-Hsyang $\mathrm{Chu}^{2,3}$ \\ ${ }^{1}$ Department of Optoelectric Physics, Chinese Culture University, Taipei, Taiwan \\ ${ }^{2}$ Institute of Space Science, National Central University, Chung-Li, Taiwan \\ ${ }^{3}$ Taiwan Ocean Research Institute, National Applied Research Laboratories, Kaohsiung, Taiwan \\ Correspondence should be addressed to Yen-Hsyang Chu; yhchu@jupiter.ss.ncu.edu.tw
}

Received 7 July 2016; Revised 19 September 2016; Accepted 10 October 2016; Published 23 February 2017

Academic Editor: Weimin Huang

Copyright (c) 2017 Chien-Ya Wang et al. This is an open access article distributed under the Creative Commons Attribution License, which permits unrestricted use, distribution, and reproduction in any medium, provided the original work is properly cited.

\begin{abstract}
It is well known that the primary targets responsible for first-order sea echoes observed by a High-Frequency (HF) radar are the advancing and receding ocean waves with the wavelengths at Bragg scales. However, in light of the fact that the ionospheric sporadic $\mathrm{E}$ (Es) and $\mathrm{F}$ layers may be present in the viewing range of the HF radar for ocean wave detection, the radar returns reflected from the $\mathrm{F}$ and Es layers may significantly contaminate the ocean wave power spectrum. The characteristics of the first-order sea echoes and ionospheric interferences measured by the CODAR-SeaSonde in Taiwan area are analyzed and presented in this article. The coherences and phases of the normalized cross spectra of the sea and ionospheric echoes between different pairs of the receiving channels are calculated, respectively. One of the striking features presented in this report is that the ionospheric echo heights scaled from the ionogram observed by the Chung- $\mathrm{Li}$ ionosonde are about $30 \mathrm{~km}$ lower than those observed by the DATAN CODARSeaSonde. It is also found that the coherences of the sea echoes are generally smaller than those of the ionospheric echoes by about $15 \%$ on average, and the phase fluctuations (standard deviations) of the sea echoes are substantially larger than those of the ionospheric layer reflection echoes. In addition, statistics show that the sum of the mean phases of the ionospheric echoes between the three receiving channel pairs is approximately zero, while it is not for the sea echoes. These results seem to suggest that the use of the discrepancies in the characteristics of the coherences and phases between the sea and ionospheric echoes may provide a potential means to be helpful to distinguish the sea and ionospheric echoes in the CODAR-SeaSonde observed cross power spectrum.
\end{abstract}

\section{Introduction}

Taiwan is a large island covering an area of about $35,883 \mathrm{~km}^{2}$ with a total coastline length of approximately $1,200 \mathrm{~km}$. This island is in a subtropical monsoon region with frequent occurrences of mesoscale systems in spring, tropical cyclone (typhoon) and convective storms during the summer, and frontal system with strong wind velocity and heavy rainfall in the winter. These various wind systems may drive local sea surface water to form varied and different currents in the ocean surrounding Taiwan Island. In addition to the wind-driven surface currents caused by the abovementioned weather systems, the interaction between the western boundary current and the persistent warm current Kuroshio combined with the rough and rugged seafloor topography makes the current system around Taiwan more complex
[1]. Besides the main island, there are more than 100 small islands distributed in the near coast region $100 \mathrm{~km}$ from the main island, which may play a role in altering the current velocity and direction. Consequently, the ocean condition is complicated, and the safety of the ships voyaging nearby Taiwan will be potentially threatened. In order to routinely monitor the current and the sea state surrounding Taiwan, the Taiwan Ocean Radar Observing System (TOROS) that consists of more than 17 sets of CODAR-SeaSonde radars was established in 2009 and operated and maintained by Taiwan Ocean Research Institute (TORI), National Applied Research Laboratories (NARL). The map of the TOROS-observed hourly surface current velocity vectors around Taiwan can be found on the website http://med.tori.org.tw/TOROS/.

Since the first observation of the Doppler spectrum of sea surface wave echoes recorded by a HF radar operating 
at $13.56 \mathrm{MHz}$ made by Crombie [2], the field of radar oceanography that aims to remotely measure and monitor the sea current and the sea state by using radars operated at various frequencies has emerged and nowadays becomes an indispensable field to the community of marine science and technology. The observed Doppler spectrum of the sea echoes is primarily composed of two types of spectral components originating from different sources. One is the first-order spectral components that result from Bragg scatter (or, more precisely, diffraction) of the traveling ocean gravity waves with the wavelength of one-half of the incident radar wavelength and characterized by two very sharp spectral peaks with almost identical Doppler frequency shifts but opposite signs. The angular Doppler frequency shift $\omega_{B}\left(=2 \pi f_{B}, f_{B}\right.$ is Doppler frequency shift) of the first-order spectral peaks is given below [2]:

$$
\omega_{B}= \pm \sqrt{2 g k_{0}}
$$

where the plus (minus) sign of $\omega_{B}$ represents the ocean wave propagating toward (away) the radar, $g$ is the gravitational acceleration $\left(9.8 \mathrm{~m} \mathrm{~s}^{-2}\right)$, and $k_{0}$ is the incident radar wave number $\left(k_{o}=2 \pi / \lambda, \lambda\right.$ is radar wavelength). For a HF radar with a central frequency of $4.58 \mathrm{MHz}$, the corresponding Bragg diffraction frequency $f_{B}$ of the sea echo is $0.218 \mathrm{~Hz}$. Another spectral type is the second-order components that are present in a form of a spectral continuum surrounding the first-order spectral peaks, which are thought to be generated through an indirect two or more steps' scattering (or reflecting) process of the radar waves that are generated by the ocean waves with relevant wave vectors and eventually the scattered waves are received by the radar [3].

In addition to the spectral components of the sea echoes, the radar returns reflected from ionospheric $\mathrm{F}$ and sporadic E (Es) layers can also frequently appear in the Doppler spectrum observed by a HF radar with echo range larger than $200 \mathrm{~km}$. The Es layers at low and middle latitudes, which mainly occur in a height range from about 90 to $125 \mathrm{~km}$, are primarily formed through the convergence effect of neutral wind shear on ionization particles [4]. The neutral winds in ionospheric E region at low latitude over Taiwan are dominated by semidiurnal tides that are characterized by a descending rate of $0.9-1.6 \mathrm{~km} / \mathrm{hr}$ [4]. The maximum frequency of the HF wave that can be reflected by the sporadic E layer can be as large as $30 \mathrm{MHz}$ or more, depending on solar activity, incident angle of the EM wave, and local ionospheric condition [5]. It is noteworthy that the Es layer occurs most frequently in summer during the local time (LT) between 6 LT and around local midnight. There is a tendency for the Es layer to occur less frequently in winter during the morning period 3-6 LT. In addition to the Es layer, the ionospheric echoes reflected from normal $F$ layers, that is, F1 and F2 layers that occasionally appear in the height below $250 \mathrm{~km}$, may occasionally be detected by CODAR-SeaSonde and consequently contaminate the Doppler spectrum of the sea echoes backscattered from ocean waves. The ionospheric echoes may seriously contaminate and interfere the sea echo Doppler spectrum, leading to severe degradation of the quality of the retrieved current and sea state beyond the range of about $90 \mathrm{~km}$ where the ionospheric layers exist.

Because the echoing mechanisms responsible for the sea echoes and ionospheric echoes are very different, it is expected that the characteristics of the radar returns backscattered from sea surface waves will be different from those reflected by the ionospheric layers. Note that almost all of the ionospheric echoes received by the FMCW CODAR-SeaSonde operating at High-Frequency (HF) band are reflected from overhead ionospheric layers usually containing electron density irregularities at various scales that are moving in the ionosphere. As a result, the ionospheric echoes in a range-Doppler frequency-intensity plot is characterized by relatively intense backscatter, limited range extent, small mean Doppler shift, and broad spectral width. In addition, the second-order sea echoes and radio interferences from unknown sources may occasionally appear in the spectral window that the ionospheric echoes occupy in Doppler spectral domain. Therefore, developing a reliable and robust approach to discern and separate ionospheric echoes from these nonionospheric signals is very crucial to improve the data quality of the CODAR-SeaSonde. In this article, an attempt is made to investigate the discrepancies in the amplitudes (coherences) and phase angles of the cross spectra between sea echoes and interference and ionospheric layer echoes. It appears that the coherence and the phase angle may serve as effective indicators for the discrimination of the echoes from various sources in Doppler spectrum. This article is organized as follows. The data employed for this research and the background of cross spectral analysis are described in Section 2. Statistical properties of amplitudes and phases of the cross spectra for the sea echoes and ionospheric echoes are presented in Section 3. Discussion is made in Section 4, and conclusions are drawn in Section 5.

\section{Signal Processing and Cross Spectral Analysis of Radar Returns}

The radar returns employed in this study are observed by the CODAR-SeaSonde located at DATAN $\left(25.02^{\circ} \mathrm{N},{ }^{\circ} 121.06^{\circ} \mathrm{E}\right)$, Taiwan, for the period 15 June-31 July, 2015. The radar parameters set for the radar observation are listed below. The central frequency of the radar wave is $4.58 \mathrm{MHz}$ (corresponding to a wavelength of $65.5 \mathrm{~m}$ ), the bandwidth B of the transmitted linear frequency modulation (FM) pulse is $40.439 \mathrm{KHz}$, the FM pulse repetition frequency PRF (or pulse swept rate) is $1 \mathrm{~Hz}$, the number $M$ of samples (or range bins) in a FM pulse for range determination is 4096 at a sampling interval $\Delta t$ of $243 \mu \mathrm{s}$, the blank period is $1.9456 \mathrm{~ms}$, and the blank delay is $8.55 \mu \mathrm{s}$. Corresponding to the radar parameters given above, the characteristics of the radar returns can be specified below: the nominally maximum range $\left(R_{m}=c T / 4 \Delta t B, T\right.$ is the FM pulse length) set for the radar observation is about $7500 \mathrm{~km}$; the practical range extent that the radar echoes can be collected is from $12.9 \mathrm{~km}$ to $291.84 \mathrm{~km}$; the range resolution ( $\Delta R=c / 2 B, c$ is light speed, $B$ is bandwidth) of the radar returns at each range bin is $3.7 \mathrm{~km}$; the time resolution of the observed radar returns is $1 \mathrm{~s}$; the Nyquist frequency 
$\left(f_{\mathrm{Ny}}=1 / T\right)$ of the observed Doppler radar spectrum is $0.5 \mathrm{~Hz}$ and the corresponding maximum Doppler velocity of the radar echoes that the radar can resolve is about $16.4 \mathrm{~m} / \mathrm{s}$.

In order to obtain information on range and Doppler frequency of the radar returns, the processes of analyzing radar signal of a FMCW radar are very different from those of a conventional pulse radar operating at a specific carrier frequency. For the latter, the target range is determined from the propagation time of the pulsed radar returns from the target. The echoes are detected by the radar receiver to generate complex quadrature signal (i.e., in-phase and quadrature, I/Q in short, components) after passing through mixer and matched filter. The I/Q components are, respectively, sampled by analog-to-digital converters (ADC) at a time step controlled by a precise master clock to obtain the information of range gates with a range resolution $\Delta R$ given by $\Delta R=c \tau / 2$ and $\tau$ is the transmitted radar pulse length. The Doppler frequency shifts of the complex radar returns at a specific range bin are then calculated in terms of Fourier transform algorithm. As for the CODAR-SeaSonde FMCW radar implemented at DATAN, the sampled output signals of a FM pulse from the mixer and analog-to-digital convertor (ADC) of the receiver are first processed by a 4096-point FFT algorithm to obtain spatial distribution of the echo amplitude over range within the FM pulse. The Fourier transform of the time series of the complex radar returns of the successive FM pulses at a specific range bin for each receiving channel is then performed by using a 1024-point FFT algorithm to obtain a 17-min averaged Doppler spectrum that contains the Doppler velocity information of the targets at this range bin. We then calculate the cross spectra of the radar returns for every pairs of the three receiving channels. The normalized complex cross spectrum $N_{i j}$ of the complex autospectra $S_{i}$ and $S_{j}$ for the $i$ th and $j$ th receiving channels has been widely used by the community of radar oceanography to extract the sea surface information from the radar returns detected by difference receiving channels, which is defined as follows:

$$
N_{i j}=\frac{\left\langle S_{i} S_{j}^{*}\right\rangle}{\left\langle\left|S_{i}\right|^{2}\right\rangle^{1 / 2}\left\langle\left|S_{j}\right|^{2}\right\rangle^{1 / 2}}=A \exp \left(i \Delta \phi_{i j}\right),
$$

where $S_{i}$ and $S_{j}$ are, respectively, the autospectra of the $i$ th and $j$ th receiving channels, $\left\langle S_{i} S_{j}^{*}\right\rangle$ is the ensemble averaged cross spectrum of $S_{i}$ and $S_{j}$,* represents complex conjugate, $A$ is coherence defined as the modulus of the normalized $\left\langle S_{i} S_{j}^{*}\right\rangle$ that signifies correlation of the echoes between $S_{i}$ and $S_{j}$, and $\Delta \phi_{i j}$ is the phase difference of the echoes between $i$ th and $j$ th receiving channels that is defined below:

$$
\Delta \varphi_{i j}=\phi_{i}-\phi_{j} .
$$

Note that the value of $A$ tends to be small and fluctuates randomly in the spectral frequency domain for uncorrelated random noises or radar returns from diffusive targets distributed uniformly and randomly in echoing region, and its value is expected to approximate 1 for the echoes from highly localized and structured targets with high signal-to-noise ratio (SNR). Theoretical analysis shows that the magnitude of the coherence is a function of signal-to-noise ratio (SNR) and the number of raw spectra for the ensemble average $[6,7]$. From $\Delta \phi_{i j}$, the spatial location of the target in echoing region can be obtained, provided the lengths of the baselines between spaced antenna pairs are known. It is evident that, for a radar with 3 receiving channels, the summation of the phase differences of the radar echoes from distinct and localized target should comply with the following relation:

$$
\Sigma \Delta \phi=\Delta \varphi_{21}+\Delta \phi_{32}+\Delta \phi_{13} \sim 0 .
$$

However, for the echoes from diffusive targets or random noises, their phase differences between the receiving channels will not satisfy the above relations.

In general, the HF radar Doppler spectrum of the sea surface echoes is dominated by two prominent first-order spectral peaks generated from the backscattered radar returns from the ocean waves with a Bragg wavelength at one-half of the incident radar wavelength. The ocean current can be estimated from the Doppler shift of the first-order peaks with respect to their theoretical Bragg frequencies in the spectral domain [8]. In addition to the first-order spectral components, the second-order spectral peaks that are present in a form of a spectral continuum surrounding the firstorder spectral peaks can usually be seen in the sea echo Doppler spectrum. The second-order echoes are thought to be generated through a two-step scattering process [3]. Namely, the incident radar wave vector $\mathbf{k}_{o}$ first interacts with the ocean wave $\mathbf{k}$ to produce an intermediate scattering radar wave vector $K$ that subsequently interacts with another pertinent ocean wave vector $\mathbf{k}^{\prime}$ to generate second scattered radar wave that can be detected by the radar. The ocean wave vectors that interact with the radar waves and are eventually responsible for the generation of the second-order echoes should fulfill the following constraint [3]:

$$
\overrightarrow{k^{\prime}}+\vec{k}=-2 \overrightarrow{k_{0}} \text {. }
$$

Therefore, it is anticipated from (5) that there are a number of combinations of the ocean wave vectors $\mathbf{k}$ and $\mathbf{k}^{\prime}$ that can produce the second-order echoes. In light of the fact that the second-order echoes are resulting from the ocean waves with different propagating directions and wavelengths, their coherences are expected to be low in values and phase differences of the cross spectra are disorganized in the spectral domain.

\section{Statistical Results of Cross Spectral Analysis}

In order to perform cross spectral analysis for obtaining coherence and phase difference of the radar echoes, a 1024sec time series (corresponding to a duration of 17 minutes) of the radar echoes at 1-sec time resolution at every range bin is first divided into 4 segments and each segment of the time series is analyzed by a 256-point FFT to obtain raw Doppler spectra. As a result, the spectral resolution of the raw Doppler spectrum will be approximately $0.004 \mathrm{~Hz}$. The coherence and phase difference of the radar echoes for each pair of the receiving channel are then computed by taking coherent 


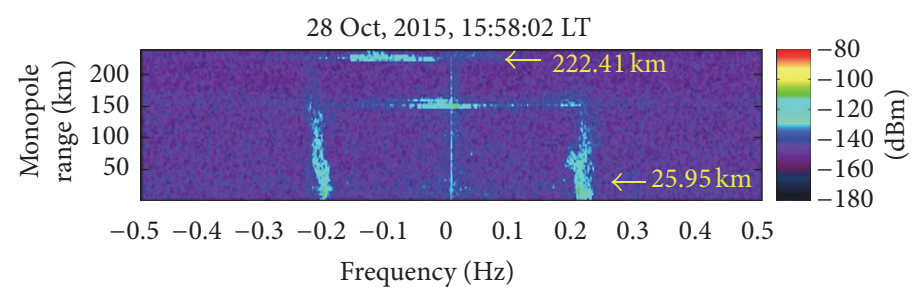

(a)

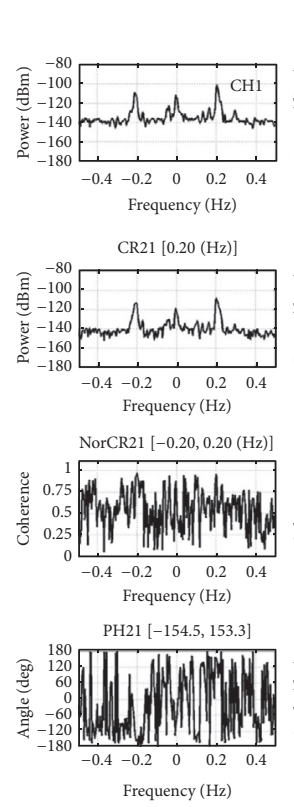

Frequency $(\mathrm{Hz})$
Sea echoes at $25.95 \mathrm{~km}$



Frequency $(\mathrm{Hz})$



Frequency $(\mathrm{Hz})$

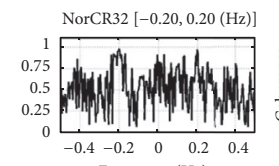

Frequency $(\mathrm{Hz})$

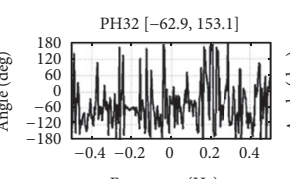

(b)

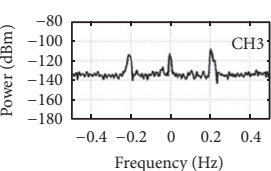

Frequency $(\mathrm{Hz})$


Frequency $(\mathrm{Hz})$

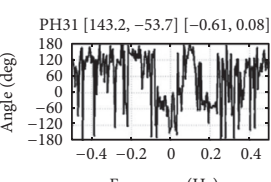

Frequency $(\mathrm{Hz})$
Ionospheric echoes at $222.41 \mathrm{~km}$
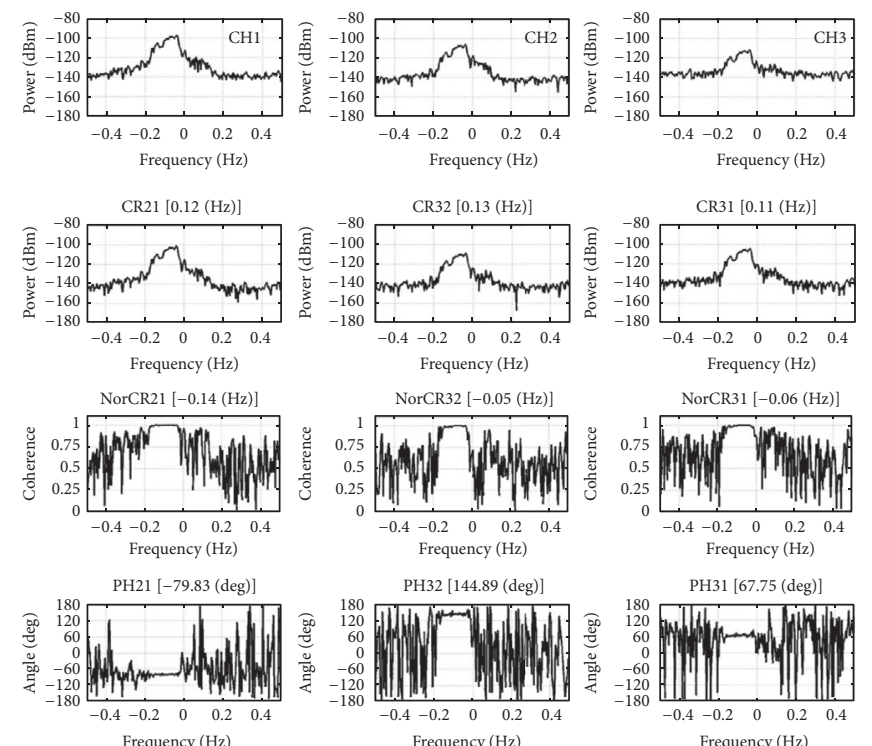

Frequency $(\mathrm{Hz})$

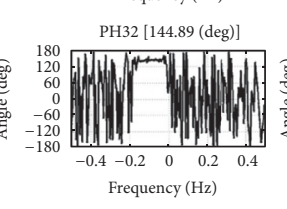

(c)

FIGURE 1: (a) shows examples of the range-Doppler frequency-intensity distribution of the sea and the ionospheric echoes recorded by the receiving channel 3 of the DATAN CODAR-SeaSonde on 15 October, 2015, at 15:58:02 LT, and (b, c) present Doppler power autospectra (first row), cross spectra (second row), coherence spectra (third row), and phase spectra (bottom row) of the normalized cross spectra for the sea echoes at $25.95 \mathrm{~km}$ (b) and ionospheric echoes at $222.41 \mathrm{~km}$ (c), respectively.

averages of the 4 successive cross spectra in accordance with (2). Note that the coherence value will be equal to 1 if no ensemble average of the cross spectrum is performed. Figure 1(a) shows an example of the range-Doppler-intensity distribution of the Doppler power spectra of the sea and the ionospheric echoes recorded by the receiving channel 3 of the DATAN CODAR-SeaSonde on 28 October, 2015, at 15:58:02 LT, and Figures 1(b) and 1(c) present the Doppler power autospectra (first row) of the sea echoes of the three receiving channels at range of $25.95 \mathrm{~km}$, the cross spectra (second row), the coherence spectra (third row), and phase spectra (bottom row) of the normalized cross spectra of the sea echoes at the same range, respectively. Note that the autospectra labeled by $\mathrm{CH} 1$ and $\mathrm{CH} 2$ (i.e., channel 1 and 2) are the observations of the two receiving loop antennas and the autospectrum marked by $\mathrm{CH} 3$ (i.e., channel 3) is the one observed by the monopole antenna of the CODAR-SeaSonde. The cross spectra marked by CR21, CR32, and CR31 are, respectively, the spectra computed from the autospectral pairs of $\mathrm{CH} 1-\mathrm{CH} 2$, $\mathrm{CH} 2-\mathrm{CH} 3$, and $\mathrm{CH} 3-\mathrm{CH} 1$ in accordance with (2). As shown in Figure 1(a) and the first and second rows in Figure 1(b), two distinct spectral peaks located at around $\pm 0.218 \mathrm{~Hz}$ are clearly seen, which correspond to advancing and receding ocean gravity waves with wavelength of $32.75 \mathrm{~m}$ that are responsible for the first-order radar echoes through Bragg backscatter. From the coherence spectra (the third row of Figure 1(b)), it is clear to see that the distribution patterns of the coherences are very organized and structured in the frequency band characterized by high coherence value and intense echo power, signifying strong correlation between the sea echoes detected by different pairs of the receiving channels inside these Doppler frequency bands. Outside the frequency bands, the coherences decrease considerably in values and vary irregularly with the Doppler frequency. Nevertheless, as shown in bottom row of Figure 1(b), the phases of the cross spectra fluctuate randomly with the Doppler frequency.

Analogous to the sea echoes, Figure 1(a) presents examples of the Doppler spectra of the ionospheric echoes at ranges $150 \mathrm{~km}$ and $220 \mathrm{~km}$, respectively, that occurred on October 28, 2015, at 15:58 LT. The former is believed to originate from the reflection of sporadic E layer and the latter is thought to reflect from $\mathrm{F}$ layer. In order to validate the sources of these ionospheric echoes, concurrent ionogram 


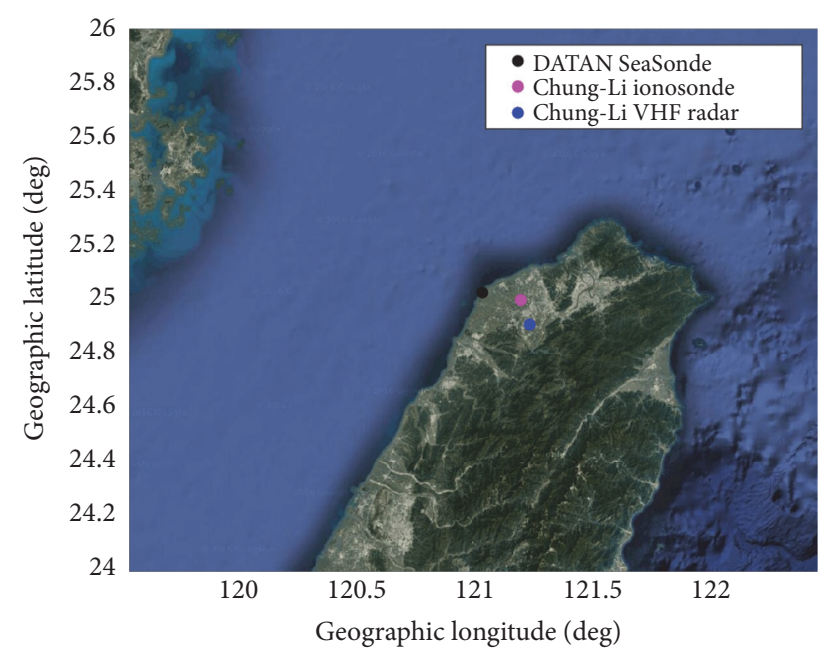

FIgURE 2: Geographic locations of DATAN CODAR-SeaSonde, Chung-Li ionosonde, and Chung-Li VHF radar site.

observed by the Chung-Li ionosonde that is an instrument vertically transmitting a FM pulse with a frequency range of $0.5-30 \mathrm{MHz}$ to exclusively detect the echoes from ionospheric layers and electron density irregularities is adopted for comparison. This ionosonde is routinely operated and maintained by National Communication Council (NCC). For the characteristics of the Chung-Li ionosonde, please refer to $\mathrm{Chu}$ et al. [9]. The geographic locations of the DATAN SeaSonde and the Chung-Li ionosonde are shown in Figure 2. Note that the echo traces recorded by ionogram can reveal the vertical structures of different ionospheric layers, including layer height, peak electron density, and plasma irregularities. Figure 3 presents the Chung-Li ionosonde-observed ionogram that is almost concurrent with the CODAR-SeaSonde echoes presented in Figure 1. The echo traces marked by $\mathrm{O}$-wave and $\mathrm{X}$-wave represent the right-hand polarized ordinary wave and left-hand polarized extraordinary wave, respectively, that are separated from a linear polarized wave when the wave propagates into ionosphere [10]. From Figure 3, the critical frequency of the F layer is about $15.2 \mathrm{MHz}$ that is scaled from the normal $\mathrm{O}$-wave trace at the point of maximum frequency, which corresponds to a peak electron density of $2.87 \times 10^{12}$ electron $/ \mathrm{m}^{3}$. For the waves with frequencies larger than the critical frequency, they will penetrate through the ionosphere and are not detected by the ionosonde. In addition to the normal $F$ layer traces, the 2nd and 3rd reflections of the F layer traces can also be seen occasionally in the ionogram, which are formed by multiple bounces of the waves between ionospheric $\mathrm{F}$ layer and earth surface. In addition, the virtual heights of the ionospheric echoes reflected from $\mathrm{F}$ and Es layers are, respectively, at around 150 and $220 \mathrm{~km}$, which are consistent with the ranges of the ionospheric echoes observed by CODAR-SeaSonde shown in Figure 1. A comparison between Figures 1 and 3 supports the assertion that the CODAR-SeaSonde-observed ionospheric echoes at ranges around 150 and $220 \mathrm{~km}$ shown in Figure 1 are indeed resulting from the reflections of the
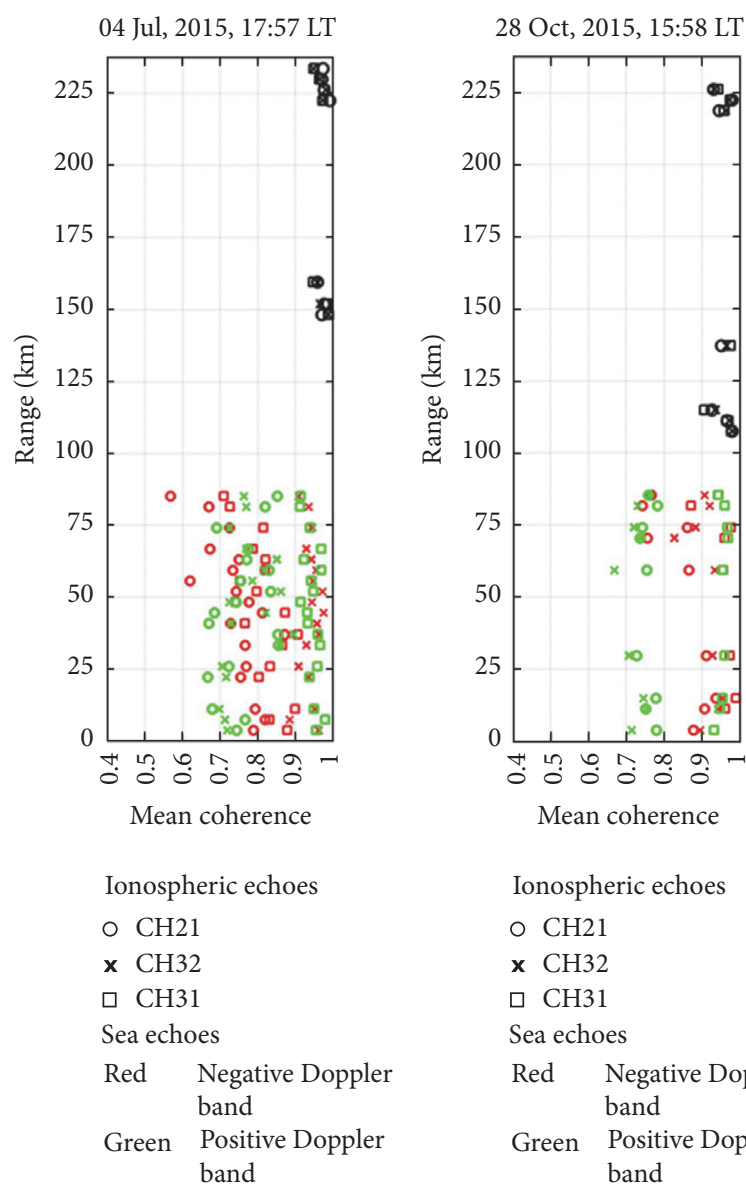

FIgURE 3: Two examples comparing coherences between sea echoes (symbols in red and green) and ionospheric echoes (symbols in black), in which red (green) symbols represent the coherences of the sea echoes computed from the negative (positive) Doppler spectral components and black symbols signify the coherences of the ionospheric echoes calculated from a Doppler spectral band from $-0.2 \mathrm{~Hz}$ to $0.2 \mathrm{~Hz}$.

ionospheric $\mathrm{F}$ and Es layers, respectively. A more detailed comparison in occurrence of ionospheric Es layer echoes between ionosonde and CODAR-SeaSonde will be made later in Discussion.

As shown in Figure 1, the spectral bandwidths of the ionospheric echoes are so broad that they extend to a frequency range covering the Doppler spectral bands of the sea echoes. Obviously, these ionospheric echoes with broad spectral width that may interfere with the sea echoes will lead to inaccurate estimates of ocean current and wave parameters. Moreover, an example presented in Figure 1 shows that the mean Doppler velocity of the ionospheric echoes at $222.41 \mathrm{~km}$ is noticeably different from zero, irrespective of the ionospheric echoes that primarily come from vertical reflection from the overhead ionospheric layers. The ionospheric echoes with relatively large mean Doppler velocities observed by CODAR-SeaSonde in Taiwan area are not uncommon. In order to realize the discrepancies in the coherences between sea echoes and ionospheric echoes, we compare the range variations of the coherences for these two 


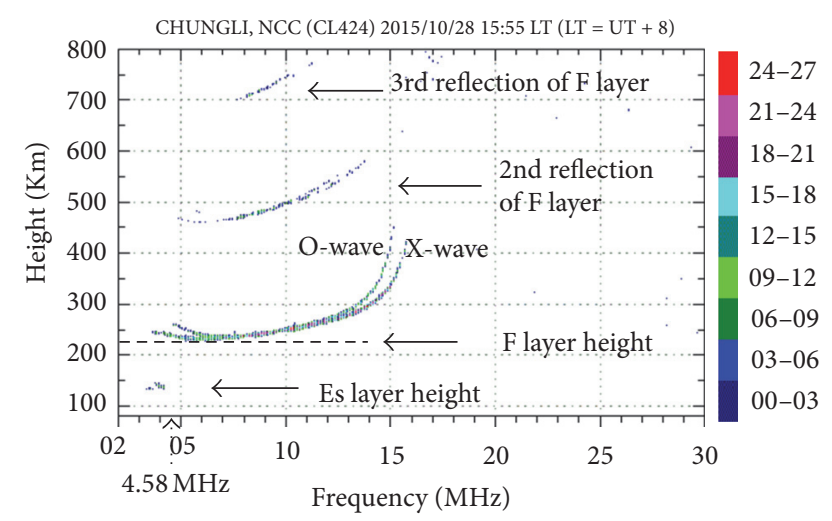

FIGURE 4: Chung-Li ionosonde-observed ionogram that is concurrent with the CODAR-SeaSonde-measured echoes shown in Figures 1 and 2 . The echo traces marked by $\mathrm{O}$-wave and $\mathrm{X}$-wave represent the right-hand polarized ordinary wave and left-hand polarized extraordinary wave, respectively. The F layer height is indicated by a dashed line, and the central operation frequency $4.58 \mathrm{MHz}$ of the DATAN SeaSonde is marked by an arrow.

types of the echoes. Figure 4 shows two examples of the variations of the coherences over range for the sea echoes (symbols in red and green) and ionospheric echoes (symbols in black) for different pairs of the receiving channels, in which the symbols open circle, cross, and open square represent the coherences of the receiving channel pairs of $\mathrm{CH} 21, \mathrm{CH} 32$, and $\mathrm{CH} 31$, respectively. The DATAN SeaSonde echo data we used for analysis are taken on July 4, 2015, 17:57 LT, and October 28, 2015, 15:58 LT, for 17 minutes. The red (green) symbols represent the coherences computed from the firstorder sea echoes with negative (positive) Doppler spectral components within the frequency bands $\pm(0.15-0.25) \mathrm{Hz}$ and black symbols signify the coherences of the ionospheric echoes calculated from a Doppler spectral band from $-0.2 \mathrm{~Hz}$ to $0.2 \mathrm{~Hz}$. The ionospheric and sea echoes that are selected for calculating coherences are required to have their peak spectral powers in respective spectral bands greater than the noise level by $15 \mathrm{dBm}$. In this study, the noise level is estimated by taking average of the lowest $30 \%$ of the spectral power components in the whole Doppler spectral domain. From Figure 4, it is clearly seen that the coherences of the ionospheric echoes are concentrated in a small range with high coherence values, whereas those of the sea echoes are spread in a wide range and substantial disagreements in the coherences between three receiving channel pairs are evident. This feature strongly implies that the coherence can be used as an plausible parameter to separate the ionospheric and sea echoes.

Figure 5 compares the histograms of the mean Doppler frequencies $(a, c)$ and the spectral widths $(b, d)$ of the ionospheric echoes $(a, b)$ and those of the sea echoes $(c, d)$. The arrow shown in (c) indicates the location of the theoretical Bragg resonant frequency of the first-order sea echoes at $0.218 \mathrm{~Hz}$ for comparison. As shown, relative to this nominal Bragg frequency, the range of the change in the observed Doppler frequencies of the first-order sea echoes is about
$0.025 \mathrm{~Hz}$. However, it is about $0.2 \mathrm{~Hz}$ for the ionospheric echoes, compared to their mean Doppler frequency that is very close to $0 \mathrm{~Hz}$. On average, the spectral width of the ionospheric echoes is about one order of magnitude larger than that of the first-order sea echoes. Note that the spectral resolution of the Doppler spectrum employed in this study is about $0.004 \mathrm{~Hz}$ that is about one order of magnitude narrower than the spectral width of the first-order sea echoes. Obviously, in addition to the windowing effect, some factors play major roles in broadening the Doppler spectrum of the first-order sea echoes, which are needed to explore in near future.

Figure 6 compares the histograms of the coherences of the ionospheric echoes $(a, b)$ with those of sea echoes $(c, d)$, in which only the results from the receiving channel pair 1 and 2 are displayed. The vertical dashed lines in each panel mark the coherence values of $0.6(\mathrm{a}, \mathrm{c})$ and $0.7(\mathrm{~b}, \mathrm{~d})$ on respective histograms for comparison. Figures 6(a) and 6(c) show the histograms of the coherences that are obtained by taking average of the 256 coherence values of the whole cross spectrum for each range bin, and Figures 6(b) and 6(d) are the averaged results of the coherence values estimated from the spectral components in the respective spectral bands that are utilized to obtain Figures 1, 4, and 5. It is evident from Figure 6 that, no matter what means are employed, the coherences of the sea echoes are systematically smaller than those of the ionospheric echoes by a factor of about $15 \%$ in average. An examination shows that about $95 \%$ of the whole cross spectrum-averaged coherences for the ionospheric echoes are greater than 0.6 , and the percentage of those for the sea echoes with the coherence values greater than 0.6 is about $16 \%$. However, this distinct discrepancy between ionospheric and sea echoes cannot be seen in the statistic results of the coherence values averaged within respective spectral bands, as shown in Figures 6(b) and 6(d). This result seems to suggest that the whole cross spectrum-averaged coherence may be a potential indicator used for discriminating the ionospheric and sea echoes in the CODAR-SeaSonde observed power spectrum.

Figure 7 presents histograms of the phases of the cross spectra for different receiving channel pairs, in which (b) is the results of ionospheric (sea) echoes and the phases are averaged for the spectral components within the respective frequency bands that are similar to those used in Figures 1,4 , and 5 . The three vertical dashed lines shown in (a) mark the mean phases of the respective major groups of the data. The summation of the mean phases of the three receiving channels pairs is about $5^{\circ}$, very close to zero. This result supports the nature of the ionospheric echoes reflected from distinct layers that the phase relation of the echoes between different pairs of the receiving channels fulfills the expression of (4). Note that there are three minor groups of the phase histograms with relative small number of the data points that seems to follow the phase relation given by (4) as well. It is believed that these groups of the data are also the ionospheric echoes that come from the ionospheric targets different from those of the major groups. Examining the distributions of the phases of the sea echoes presented in Figure 7(b) demonstrates that their phases do not follow 


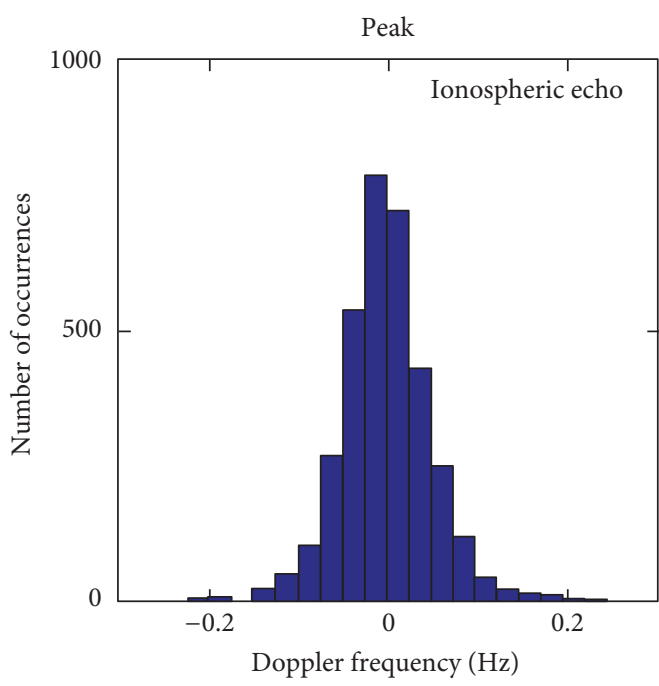

(a)

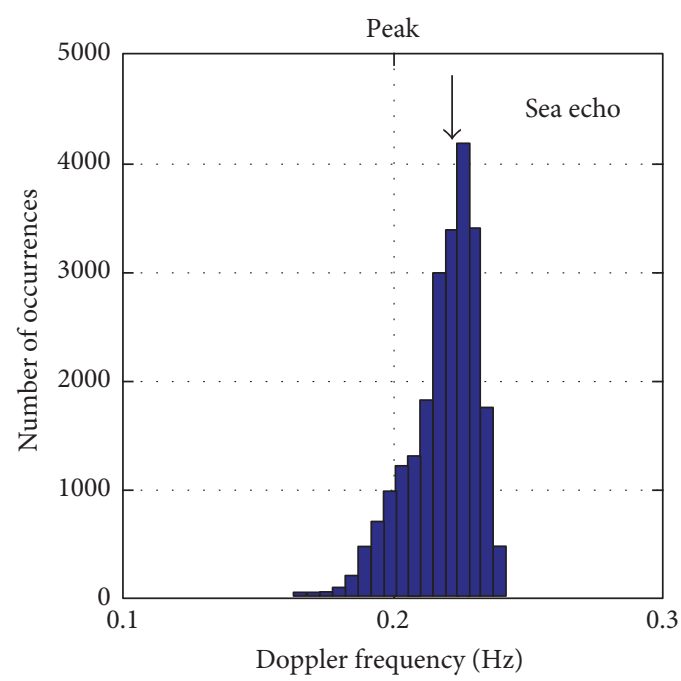

(c)

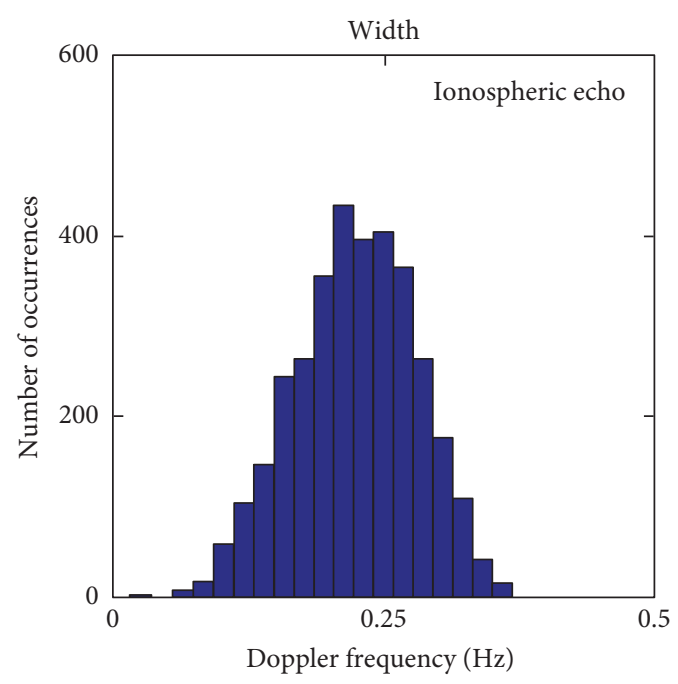

(b)

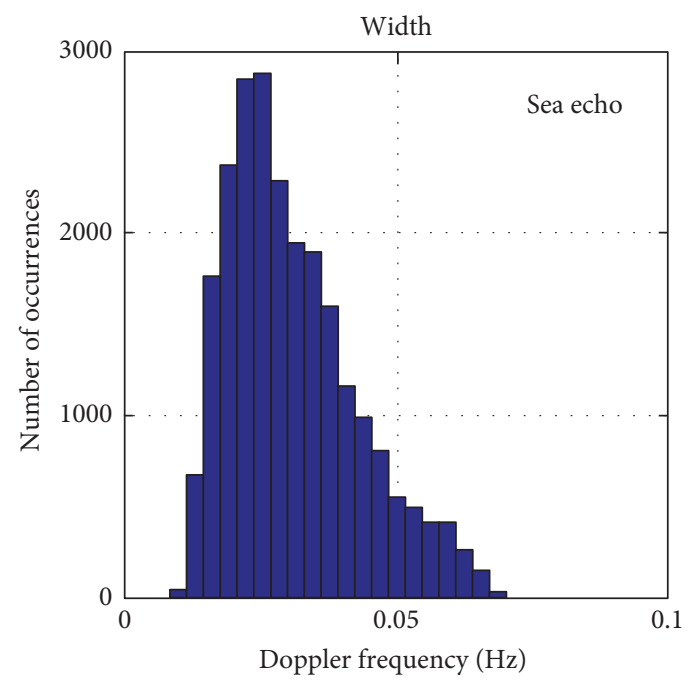

(d)

FIGURE 5: Comparison of the histograms of the spectral peak locations (a, c) and the spectral widths (b, d) of the ionospheric echoes (a, b) with those of the sea echoes $(c, d)$. The arrow shown in bottom left panel indicates the location of the first-order Doppler spectral peak of the sea echoes at $0.218 \mathrm{~Hz}$ for comparison.

the relation of (4). Obviously, this is because the ocean waves distribute randomly in the echoing region over sea; the echoing process through the diffusive Bragg backscatter will lead to a random nature of the phases of the sea echoes. As a result, their phase relation cannot be described in terms of (4).

As shown in Figures 1 and 7, the phase distributions of the ionospheric echoes in the spectral ranges with high coherences are much more structured and organized than those of the sea echoes. It is then anticipated that the degree of the phase fluctuations for the ionospheric echoes will be very different from that for the sea echoes. Figure 8 compares the histograms of the standard deviations of the phases of the ionospheric echoes (a) with those of the sea echoes (b), in which the spectral bands employed for the calculations of the standard deviations of the phases are the same as
Figures 1, 4, and 7. As expected, the overwhelming majority ( $80 \%$ or more) of the standard deviations of the phases of the ionospheric echoes for the three receiving channel pairs mainly distribute in a small range of $0^{\circ}-20^{\circ}$. However, for the sea echoes their standard deviations distribute in a relatively broad range, primarily between $0^{\circ}$ and $90^{\circ}$.

\section{Discussion}

The cross spectral analysis has been widely used by the community of radar oceanography to extract the sea surface information from the radar returns detected by difference receiving channels. As shown in Section 3, the cross spectral analysis of the radar returns may offer an opportunity to realize the correlation of the echoes between different receiving channels in spectral domain. Our analyses indicate 


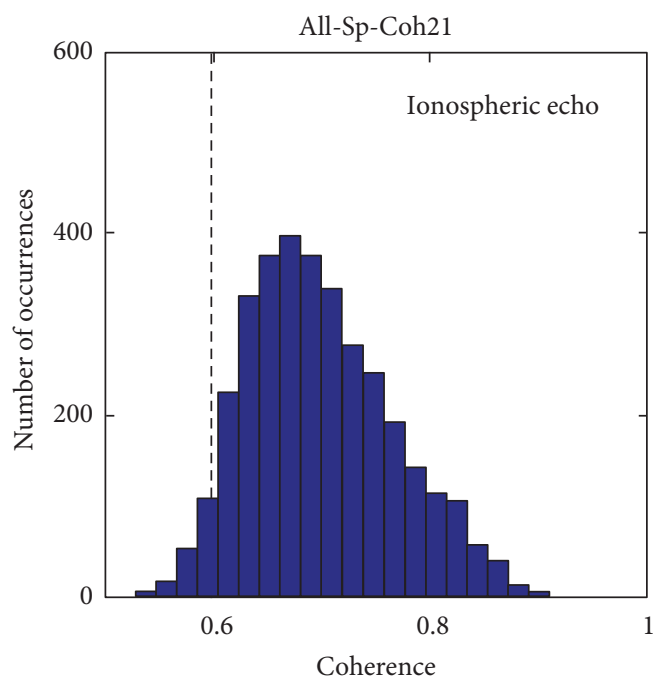

(a)

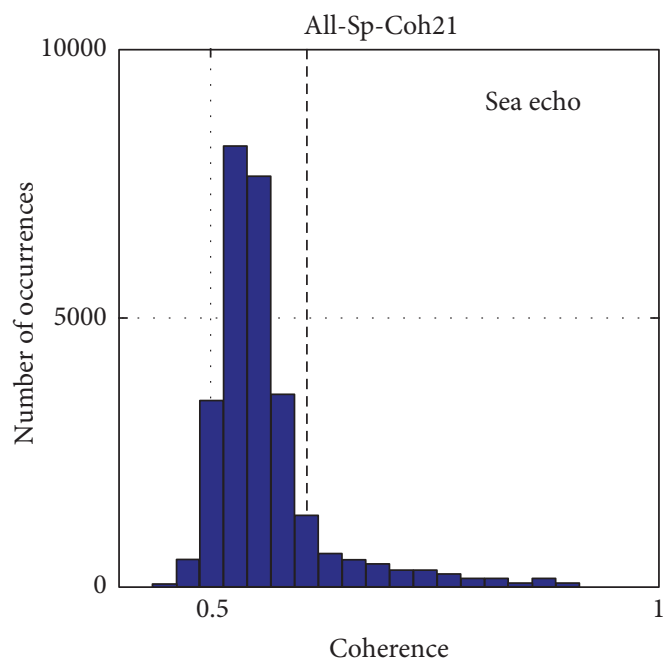

(c)

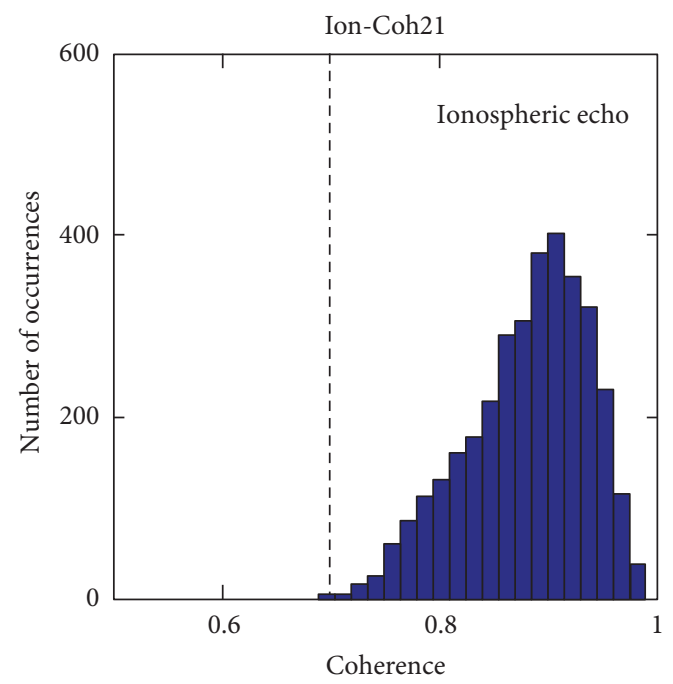

(b)

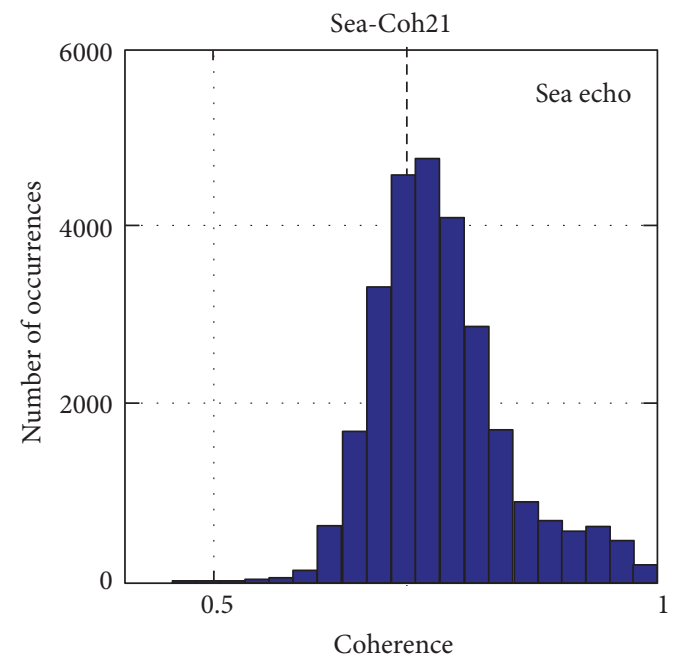

(d)

Figure 6: Comparison of the histograms of the coherences of the ionospheric echoes (a, b) with those of sea echoes (c, d), in which only the results from the receiving channels 1 and 2 are displayed. The dashed lines in every panels mark the coherence values of 0.6 (a, c) and 0.7 (b, d) on respective histograms for comparison.

that the coherences of the normalized cross spectra are high for the echoes from organized and structured targets, that is, ionospheric layers, whereas the coherences will be low for the radar returns from randomly distributed diffusive targets, that is, ocean waves, in echoing region. Additionally, for the distinct and isolated targets, such as ionospheric layers, the phase differences of the cross spectra of the echoes between receiving channel pairs also exhibit organized and structured patterns in the spectral domain and their phase relations should comply with the relation given by (4). However, for the first-order sea echoes generated from Bragg backscatter of the random ocean waves, our results show that their phase relation may not necessarily comply with the relation given by (4) due to the random nature of their phases. With these properties, the coherence and the phase of the echoes observed by a sea radar operated at HF band may be employed as indicators for the discrimination of the ionospheric echoes from the sea echoes in the spectral domain to improve the data quality of the measured current and ocean waves.

For a HF sea-wave radar with echo range larger than $200 \mathrm{~km}$, the observed Doppler spectrum is susceptible to the ionospheric echoes reflected from sporadic E (Es) layer that occurs in a height range from about 90 to $150 \mathrm{~km}$. Note that the mechanisms responsible for the formation of the Es layers vary with the geomagnetic latitudes. At geomagnetic equator, the Es layers (or Es plasma irregularities) are thought to be generated through the processes of the plasma instabilities, including two-stream or gradient drift instabilities [11]. However, at high latitude, the formations of the Es plasma irregularities are associated with the plasma instabilities or bombardment effect of charged particles from upper ionosphere [12]. At low and middle latitudes, the Es layers are primarily formed due to convergence effects 

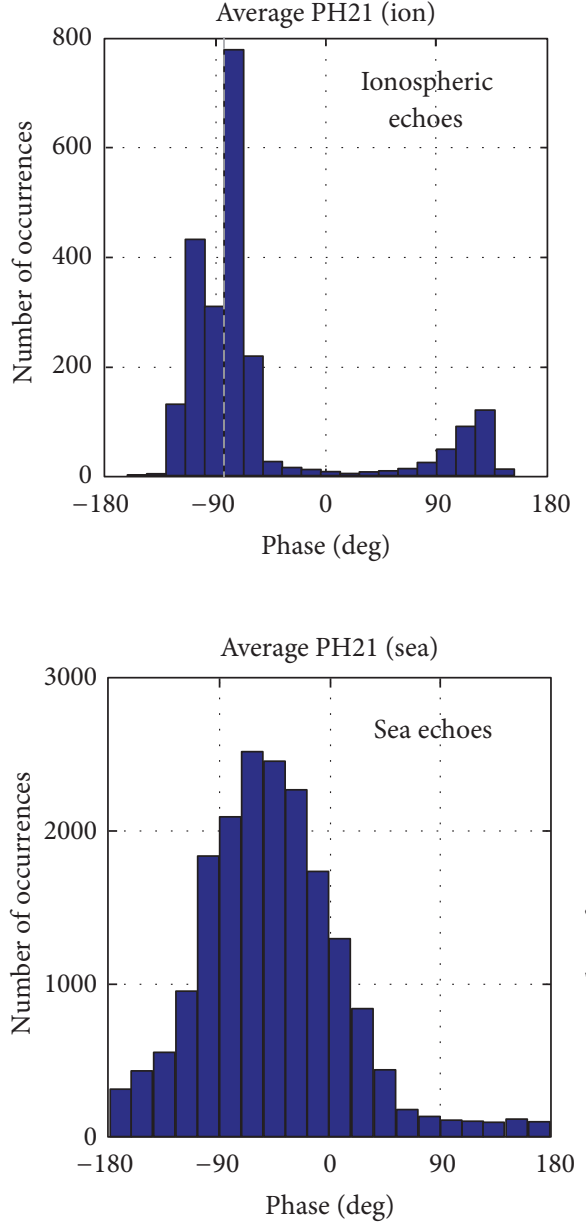

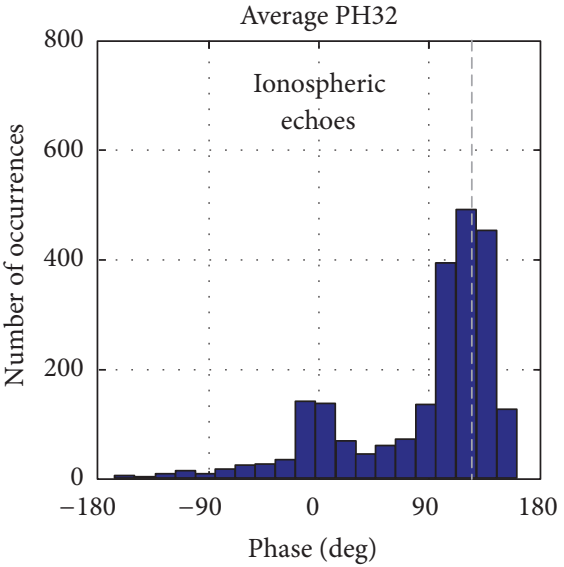

(a)

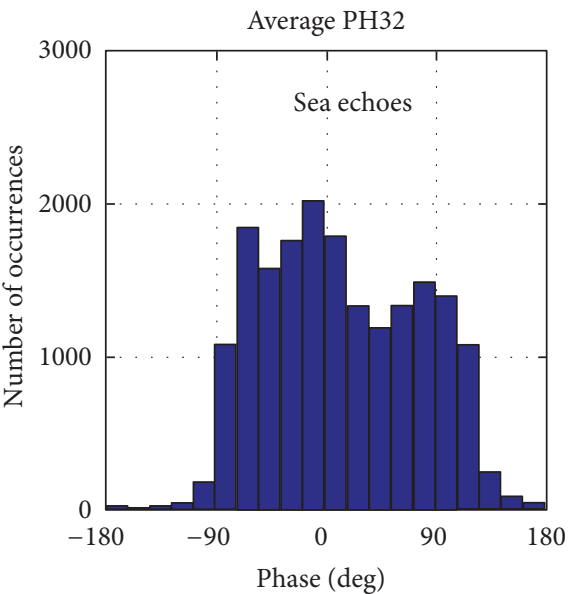

(b)


FiguRE 7: Histograms of the phases of the cross spectra for different receiving channel pairs, in which (a, b) are the results of ionospheric (sea) echoes and the phases are averaged for the spectral components within the specific frequency bands that are similar to those used in Figure 5.

of neutral wind shear and/or electric field on ionization particles $[4,13,14]$. Figure 9 compares the range-time distribution of the number of occurrences of the ionospheric echoes detected by the CODAR-SeaSonde at DATAN (b) and observed by the Chung-Li ionosonde (a) for the period from 30 June to 31 July, 2015. A prominent feature shown in Figure 9 is the distinct descent of the Es layer echoes during daytime from 6 to $18 \mathrm{LT}$ in the range extent $90-150 \mathrm{~km}$, at a descending rate of about $1.2 \mathrm{~km} / \mathrm{hr}$. Obviously, this feature is in good agreement with the descending rate of the wind shear zone of a vertically propagating semidiurnal tide [15, 16]. Therefore, the ionospheric echoes detected by CODARSeaSonde can, in principle, be used for the investigation of the characteristic and dynamic behavior of the $\mathrm{F}$ and/or Es layers in ionosphere. Although their patterns of the echo rangelocal time variations in the occurrence of the ionospheric Es layers are in general agreement with each other, there is a tendency for the echo heights of the ionosonde-observed Es layers to be about $30 \mathrm{~km}$ lower than those measured by the CODAR-SeaSonde. In addition, the number of occurrences of the ionosonde-observed Es layer echoes is also larger than that of the CODAR-SeaSonde measurements, especially during nighttime. The causes of these inconsistencies in the number of occurrence and the echo range of the Es layer between Chung-Li ionosonde and CODAR-SeaSonde may be attributed to the differences in the system characteristics, echo processing procedure, data sifting criterion, and so on. This issue will be explored in the near future to clarify the causes of these inconsistencies between these two radar systems.

Figure 10 displays the range variations of the Doppler spectra of the first-order and second-order sea echoes taken on July 10, 2015, at 04:50:05 LT, in which the Doppler spectra observed by 3 receiving antennas (two of them are identical loop antennas and the other one is monopole antenna) are presented, respectively. As shown in Figure 10(a), the second-order Doppler spectral components that appeared in a spectral region surrounding the first-order spectral peaks are clearly seen. In addition to the weak spectral continuum around direct current (DC) component with zero Doppler frequency, two noticeable second-order spectral peaks at 0.308 and $0.37 \mathrm{~Hz}$ are, respectively, clearly identified 

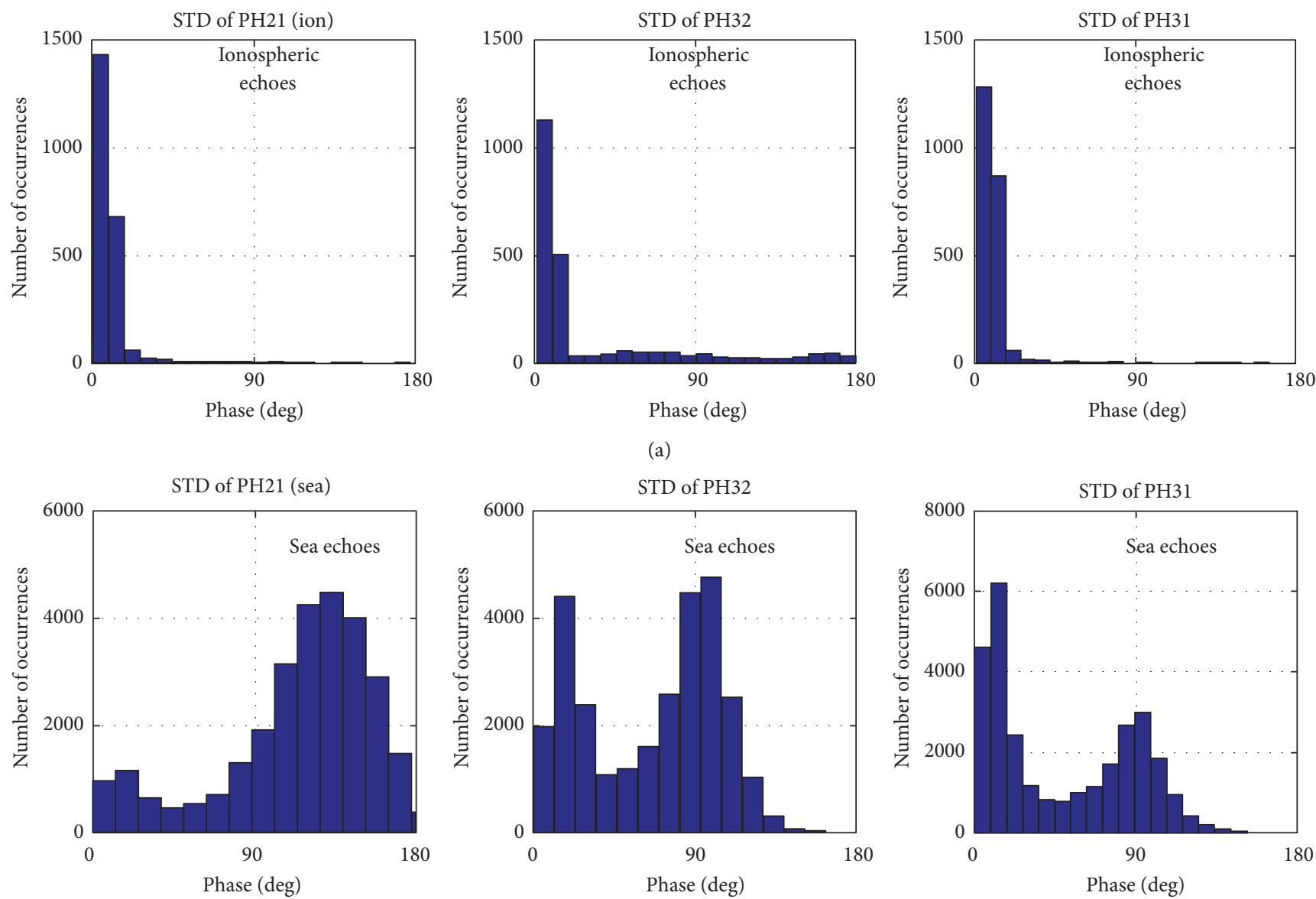

(b)

FIGURE 8: Comparison of the histograms of the standard deviations of the phases of the ionospheric echoes (a) with those of the sea echoes (b), in which the spectral bands employed for the calculations of the standard deviations of the phases are the same as Figures 5 and 7.

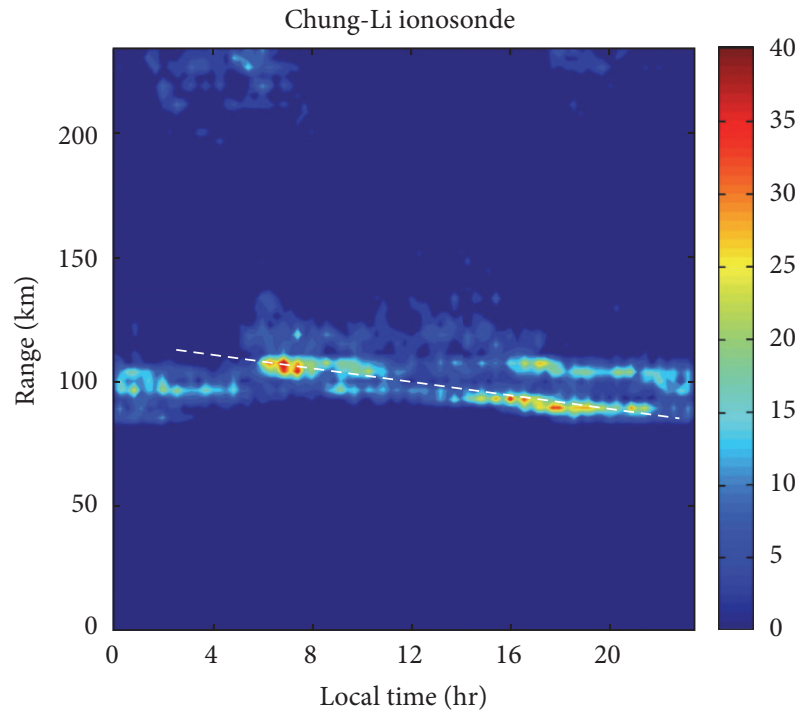

(a)

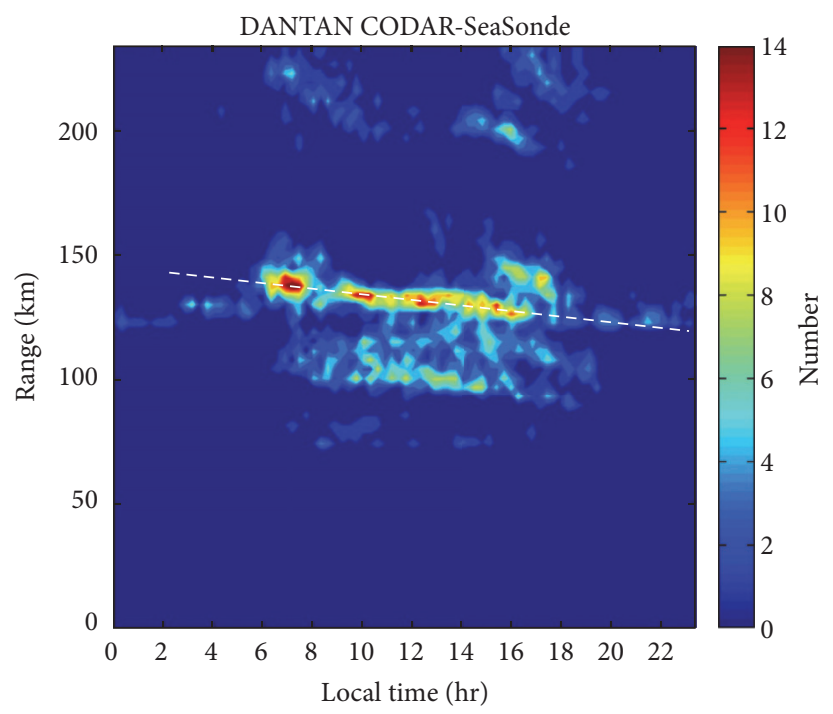

(b)

FIGURE 9: Range-local time distributions of the numbers of occurrences of the ionospheric Es layer (90-150 km) and F layer echoes (above $200 \mathrm{~km}$ ) detected by the Chung-Li ionosonde (a) and DATAN COAR-SeaSonde (b) for the period from 30 June to 31 July, 2015. 



(a)
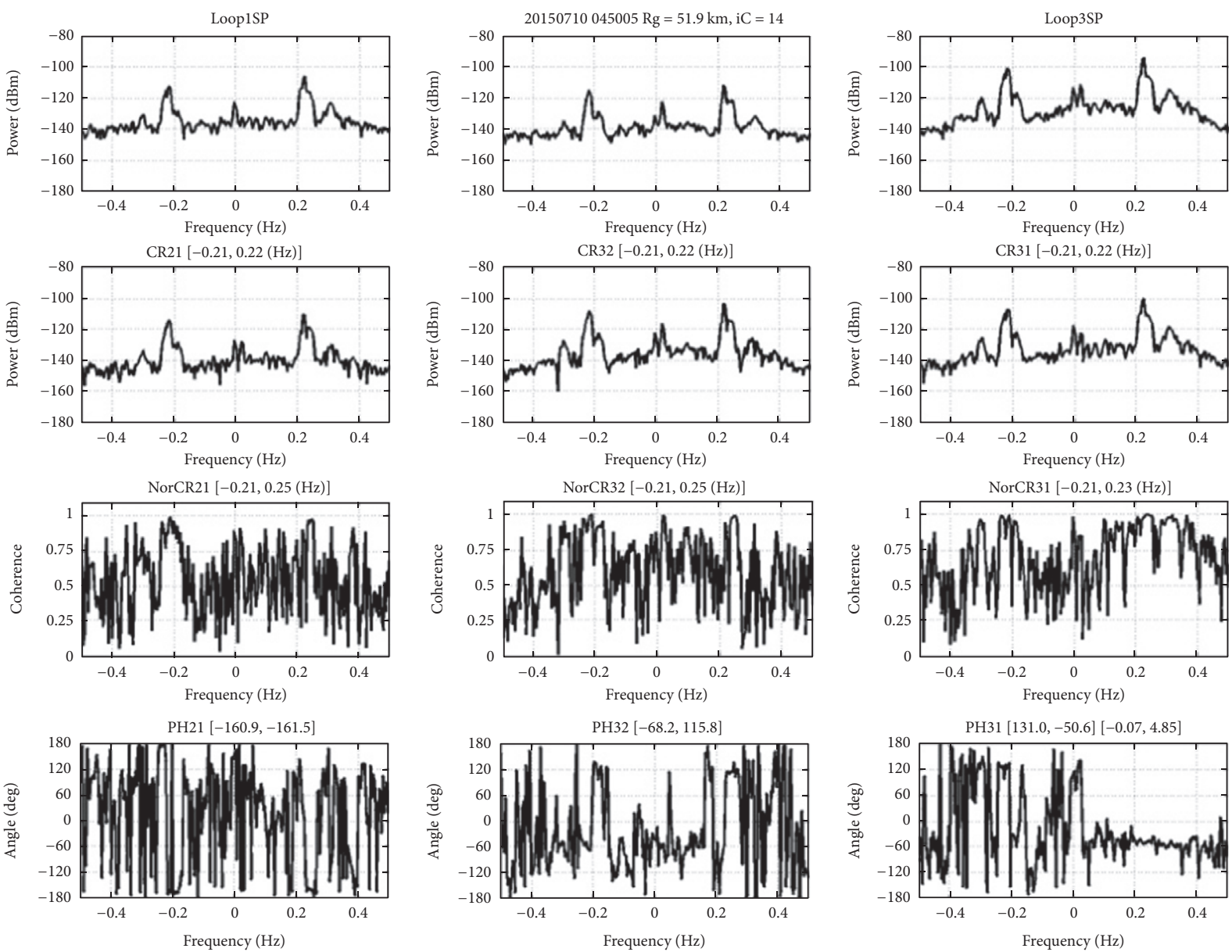

(b)

Figure 10: (a) Examples of range variations of the Doppler spectra of the first-order and second-order sea echoes. Note that the first-order spectral peaks locate at $\pm 0.218 \mathrm{~Hz}$. The top and middle panels are the Doppler spectra observed by the identical two loop antennas, and the bottom panel shows the Doppler spectra from monopole antenna. (b) Autospectra (top), cross spectra between different receiving channels (2nd panels), coherence spectra (3rd panels), and phase spectra (bottom panels) of the sea echoes for the data at range of $51.9 \mathrm{~km}$ presented in (a). 

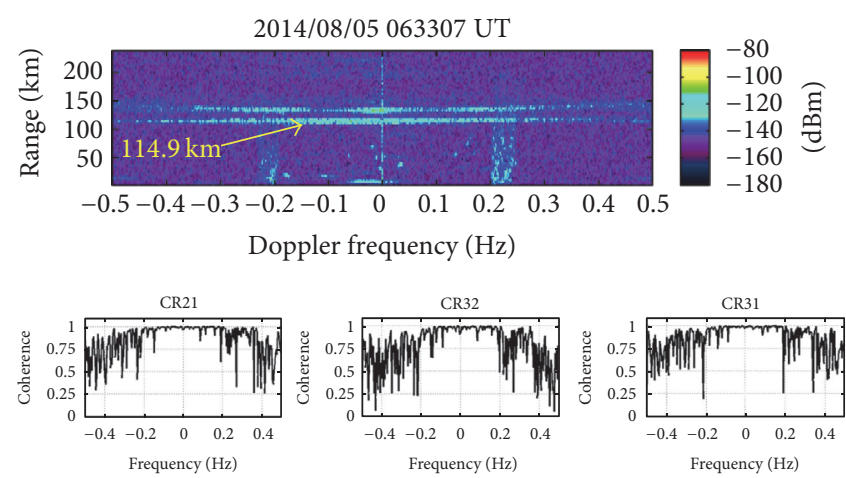

$\mathrm{PH} 2$
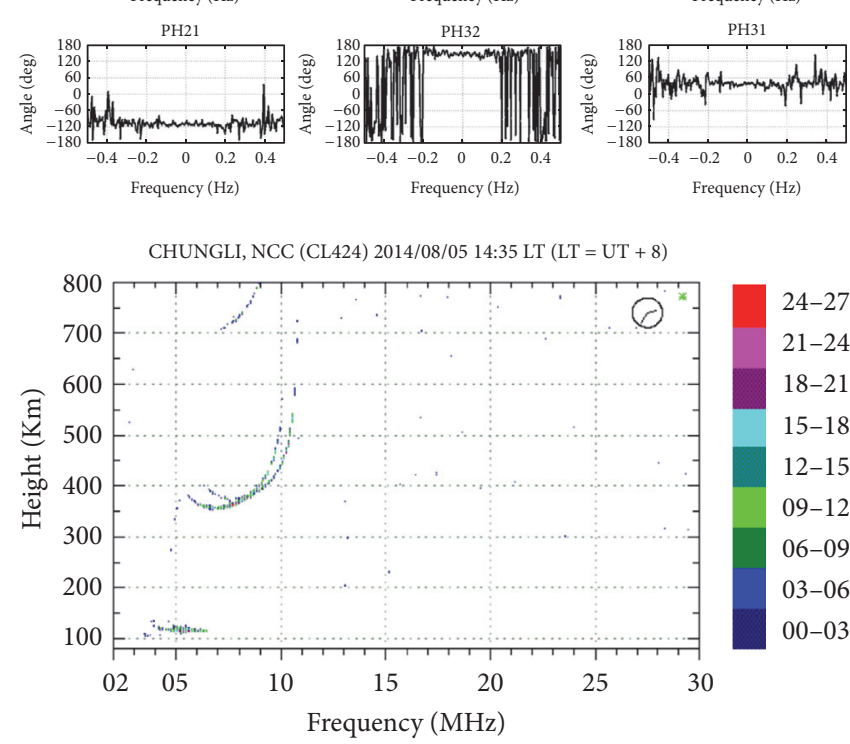

(a)
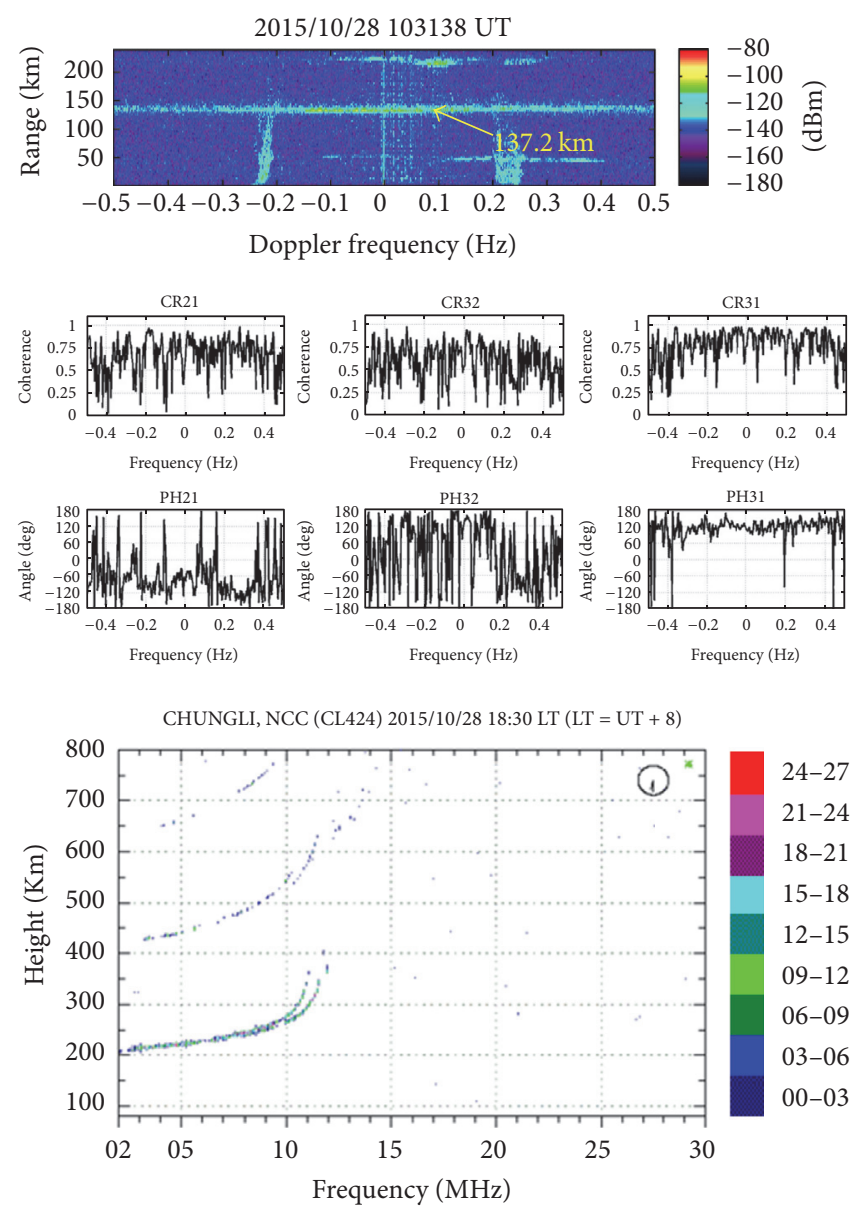

(b)

FIGURE 11: A comparison in coherence and phase angle between ionospheric Es layer echoes (a) and external radio interference (b).

in the Doppler spectra observed by the monopole antenna. These features are consistent with the theoretical prediction that the spectral peaks of the second-order sea echoes are predicted to situate at $2^{1 / 2} f_{B}$ and $2^{3 / 4} f_{B}$, where $f_{B}$ is the Doppler frequency shift of the first-order spectral peaks [17]. Figure 10(b) displays autospectra (1st row), cross spectra between different receiving channels (2nd row), coherence spectra (3rd row), and phase spectra (bottom row) of the sea echoes for the data at a range of $51.9 \mathrm{~km}$ presented in Figure 10(a). As shown, two intense first-order spectral components with significantly large coherence values that are very close to 1 are clearly seen and discerned in the power and coherence spectra of the three receiving channels, although the phases within the corresponding frequency bands of the first-order spectral peaks fluctuate considerably. However, for the second-order spectral components, their spectral appearances in the three different receiving channels are very different. They are easily discernible in the receiving channel 3, but the spectral components at $2^{3 / 4} f_{B}$ are vague and hard to distinguish in the channels 1 and 2 . As a result, the coherences of the second-order spectral components are not as vivid and organized as those of the first-order echoes in magnitude. In addition, the phase fluctuations of the second-order echoes are also random and irregular. From this case report, one should be cautious to analyze and interpret the coherence and the phase of the cross spectra of the second-order echoes detected by the CODAR-SeaSonde.

As mentioned before, the ionospheric echoes characterized by broad spectral width and limited range extent in range-Doppler frequency-intensity (RDI) plot may interfere with the Doppler spectral bands of the sea echoes, as shown in the examples presented in Figures 2 and 10. Note that the appearance of such ionospheric echoes may bear a strong resemblance to that of the radio interference from unknown source, leading to a difficulty of discerning them in RDI plot. Figure 11 compares the appearances of the ionospheric echoes and interference in RDI plots. As shown, the upper panels of (a) and (b) are, respectively, the ionospheric echoes and the interference that occupy a very broad frequency range covering the spectral bands of the sea echoes. From the ionogram shown in the bottom panels of Figure 11(a), the presence of a distinct Es layer centered at a virtual height of about $114 \mathrm{~km}$ is clearly found and is coincident with the ionospheric echoes presented in upper panel of Figure 11(a), whereas no 
2015/06/15-2015/07/31 4.58 MHz in DATAN (L-1, Avg-N30)

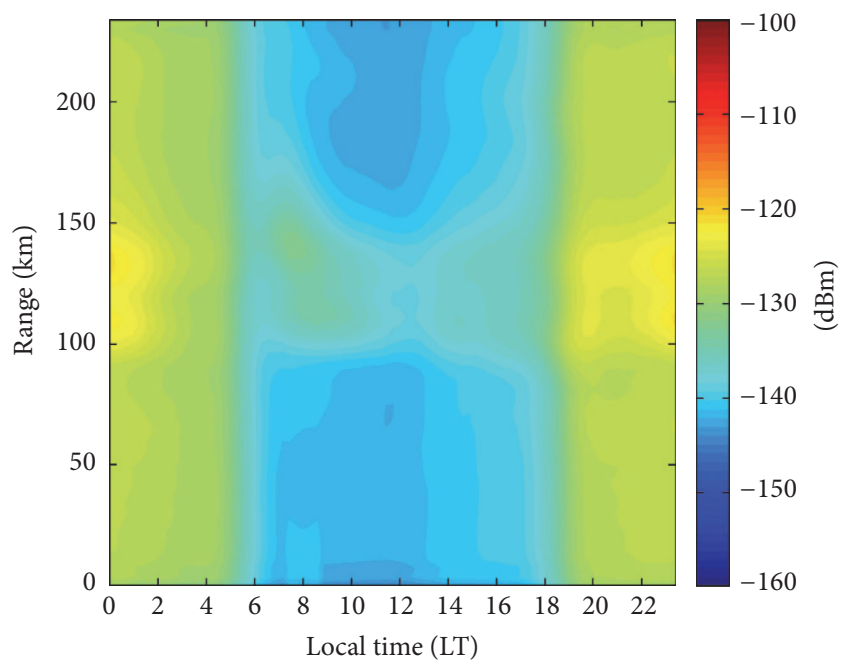

FIGURE 12: Variation of background noise over range and local time.

Es layer is found in the virtual height range $100-150 \mathrm{~km}$ in the bottom panel of Figure 11(b). Because of this, we consider the echoes that appeared at a range of $137 \mathrm{~km}$ in the upper panel of Figure 11(b) to be very likely a radio interference with unknown source. Although they are difficult to discern in RDI plot, the ionospheric echoes and the interference can be easily distinguished in terms of coherence and phase angle of normalized cross spectra. As shown in the middle panels of Figure 11, the patterns of the frequency distributions of the coherences and the phase angles for the different pairs of the receiving channels for the ionospheric echoes are very organized and structured, which are very different from those of the interference characterized by random fluctuations in the coherences and phase angles. In addition, the summation of the mean phase angles of the ionospheric echoes fully complies with the relation given by (4), but it is not for the interference. Compared to the coherent ionospheric echoes, the random properties of the interference strongly imply the incoherent nature of the signals from the unknown source. An examination of the coherences and phase angles of the sea echoes presented in Figure 11 indicates that the ionospheric echoes and external interference can significantly disrupt the spectral properties of the sea echoes, causing the degradation of the data quality of the estimated ocean current and wind wave parameters. Therefore, understanding the spectral properties of the ionospheric echoes characterized by broad spectral width and interference is very crucial to improve the data quality of a HF sea radar by coming up with an efficient ways for the data processing and analysis.

Figure 12 presents variations of background noise intensity over range and local time, in which the noise intensity is estimated by averaging the lowest $30 \%$ of the spectral power components in the observed Doppler spectrum to avoid the potential contaminations of nonocean echoes and external radio interference on the noise estimate. As shown, a striking diurnal variation of the background noise intensity is present, low during daytime and high during nighttime with a maximum difference of up to $15 \mathrm{dBm}$ in the noise intensities between daytime and nighttime. A comparison indicates that the noise level estimated from the lowest $30 \%$ of the spectral components is in general $3 \mathrm{~dB}$ smaller than that calculated from $20 \%$ of the spectral components toward the higher frequency ends in the Doppler spectrum, that is, in the frequency bands of $\pm(0.4-0.5) \mathrm{Hz}$ that are close to the Nyquist frequency, irrespective of daytime and nighttime. Note that the electromagnetic waves at lower HF bands are capable of being effectively reflected by the ionosphere. During their propagation in the ionosphere, the HF waves are susceptible to the absorption of free electrons through neutral-electron collision process in lower ionosphere to reduce their intensity through the nondeviation absorption effect that is inversely proportional to the electron density in lower ionosphere [5]. Therefore, the larger the electron density during daytime is, the lower the HF wave intensity will be, and vice versa. Figure 12 also demonstrates that, relative to the background noises in other ranges, there is a tendency for the noise level to slightly increase in a range extent between 100 and $150 \mathrm{~km}$ by about $5 \mathrm{~dB}$. A comparison between Figures 9 and 12 indicates that the slight increase in the background noise in this range extent is coincident with the occurrence of ionospheric echoes. This feature suggests that the ionospheric echoes may affect the estimate of the background noise in terms of averaging the spectral power components, no matter what methods are employed. Therefore, we should be more cautious in interpreting the range variation of the background noise intensity in the presence of the ionospheric echoes.

\section{Conclusions}

In this study, the radar returns taken by CODAR-SeaSonde at DATAN in Taiwan are analyzed. The concurrent ionospheric traces in the ionogram observed by the Chung-Li ionosonde are also employed in this study to help to identify the ionospheric echoes detected by the SeaSonde radar. We confirm that the echo traces shown in ionogram provide vital background information on vertical structures of the ionospheric layers that can be used to validate the sources of the concurrent ionospheric echoes observed by CODARSeaSonde. A comparison indicates that the ionospheric Es layer heights scaled from the ionograms observed by the Chung-Li ionosonde are in general about $30 \mathrm{~km}$ lower than those measured by the CODAR-SeaSonde. The work needs to be done in near future to examine the causes of the discrepancy in the echo heights between these two radars.

The coherences and phases of the normalized cross spectra of the sea and ionospheric echoes between different pairs of the receiving channels are, respectively, calculated. Because of their diffusive scattering nature, the degree of the phase fluctuations of the sea echoes is expected to be much larger than that of the ionospheric echoes reflected from the distinct ionospheric layers. We show in this study that the coherences of the sea echoes are generally smaller than those of the ionospheric echoes by about $15 \%$ on average, and the phase fluctuations (standard deviations) of the sea echoes are substantially larger than those of the ionospheric layer 
reflection echoes. In addition, statistics show that the sum of the mean phases of the ionospheric echoes between the three receiving channel pairs is approximate to zero, while it is not for the sea echoes. In addition, analysis shows that the coherences of the ionospheric echoes that is obtained by taking average of the spectral components of the whole cross spectra can be easily distinguishable from those of the sea echoes. Therefore, it suggest that the use of coherence and phase of the normalized cross spectra of the three different receiving channel pairs would be helpful in separating the ionospheric reflection echoes from the CODAR-SeaSonde sea echoes in the spectral domain.

\section{Competing Interests}

The authors declare that they have no competing interests.

\section{Acknowledgments}

This work is supported by the Taiwan Ocean Research Institute (TORI), National Applied Research Laboratory (NARL), Taiwan. The CODAR-SeaSonde is operated and maintained by TORI, NARL.

\section{References}

[1] J. Yang, "An oceanic current against the wind: how does Taiwan Island steer warm water into the East China Sea?" Journal of Physical Oceanography, vol. 37, no. 10, pp. 2563-2569, 2007.

[2] D. D. Crombie, "Doppler spectrum of sea echo at $13.56 \mathrm{Mc}$./s.," Nature, vol. 175, no. 4459, pp. 681-682, 1955.

[3] B. J. Lipa and D. E. Barrick, "Extraction of sea state from HF radar sea echo: mathematical theory and modeling," Radio Science, vol. 21, no. 1, pp. 81-100, 1986.

[4] Y. H. Chu, C. Y. Wang, K. H. Wu et al., "Morphology of sporadic e layer retrieved from COSMIC GPS radio occultation measurements: wind shear theory examination," Journal of Geophysical Research: Space Physics, vol. 119, no. 3, pp. 2117-2136, 2014.

[5] H. Rishbeth and O. K. Garriott, Introduction to Ionospheric Physics, Academic Press, San Diego, Calif, USA, 1969.

[6] Y. Chu and S. J. Franke, "A study of the frequency coherence of stratospheric and tropospheric radar echoes made with ChungLi VHF radar," Geophysical Research Letters, vol. 18, no. 10, pp. 1849-1852, 1991.

[7] P. R. Julian, "Comments on the determination of significance levels of the coherence statistic," Journal of the Atmospheric Sciences, vol. 32, no. 4, pp. 836-837, 1975.

[8] K.-W. Gurgel, H.-H. Essen, and S. P. Kingsley, "High-frequency radars: physical limitations and recent developments," Coastal Engineering, vol. 37, no. 3-4, pp. 201-218, 1999.

[9] Y.-H. Chu, P. S. Brahmanandam, C.-Y. Wang, C.-L. Su, and R.-M. Kuong, "Coordinated sporadic E layer observations made with Chung-Li $30 \mathrm{MHz}$ radar, ionosonde and FORMOSAT-3/COSMIC satellites," Journal of Atmospheric and Solar-Terrestrial Physics, vol. 73, no. 9, pp. 883-894, 2011.

[10] D. E. Kerr, Propagation of Short Radio Waves, vol. 13 of The MIT Radiation Laboratory Series, McGraw-Hill, New York, NY, USA, 1951.
[11] B. G. Fejer and M. C. Kelley, "Ionospheric irregularities," Reviews of Geophysics, vol. 18, no. 2, pp. 401-454, 1980.

[12] B. R. Clemesha, "Sporadic neutral metal layers in the mesosphere and lower thermosphere," Journal of Atmospheric and Terrestrial Physics, vol. 57, no. 7, pp. 725-736, 1995.

[13] J. D. Whitehead, "The formation of the sporadic-E layer in the temperate zones," Journal of Atmospheric and Terrestrial Physics, vol. 20, no. 1, pp. 49-58, 1961.

[14] T. Nygrén, L. Jalonen, J. Oksman, and T. Turunen, “The role of electric field and neutral wind direction in the formation of sporadic E-layers," Journal of Atmospheric and Terrestrial Physics, vol. 46, no. 4, pp. 373-381, 1984.

[15] Q. Wu, T. L. Killeen, D. A. Ortland et al., “TIMED Doppler interferometer (TIDI) observations of migrating diurnal and semidiurnal tides," Journal of Atmospheric and Solar-Terrestrial Physics, vol. 68, no. 3-5, pp. 408-417, 2006.

[16] C. L. Su, H. C. Chen, Y. H. Chu et al., "Meteor radar wind over Chung-Li $(24.9 \circ \mathrm{N}, 121 \circ \mathrm{E})$, Taiwan, for the period 10 25 November 2012 which includes Leonid meteor shower: comparison with empirical model and satellite measurements," Radio Science, vol. 49, no. 8, pp. 597-615, 2014.

[17] D. E. Barrick, "Extraction of wave parameters from measured HF radar sea-echo Doppler spectra," Radio Science, vol. 12, no. 3, pp. 415-424, 1977. 


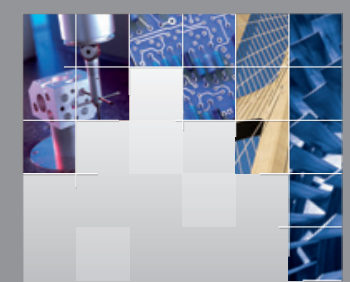

\section{Enfincering}
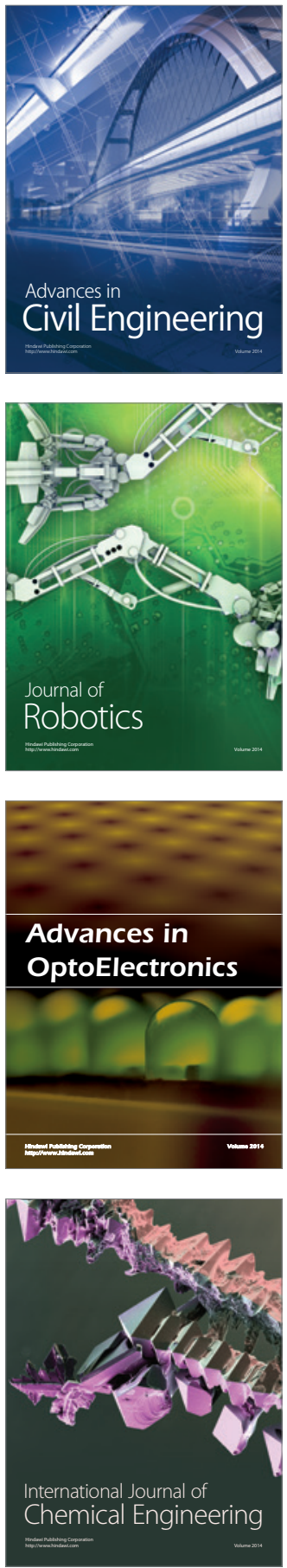

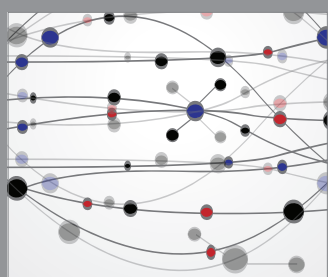

The Scientific World Journal

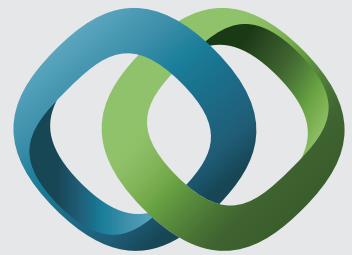

\section{Hindawi}

Submit your manuscripts at

https://www.hindawi.com
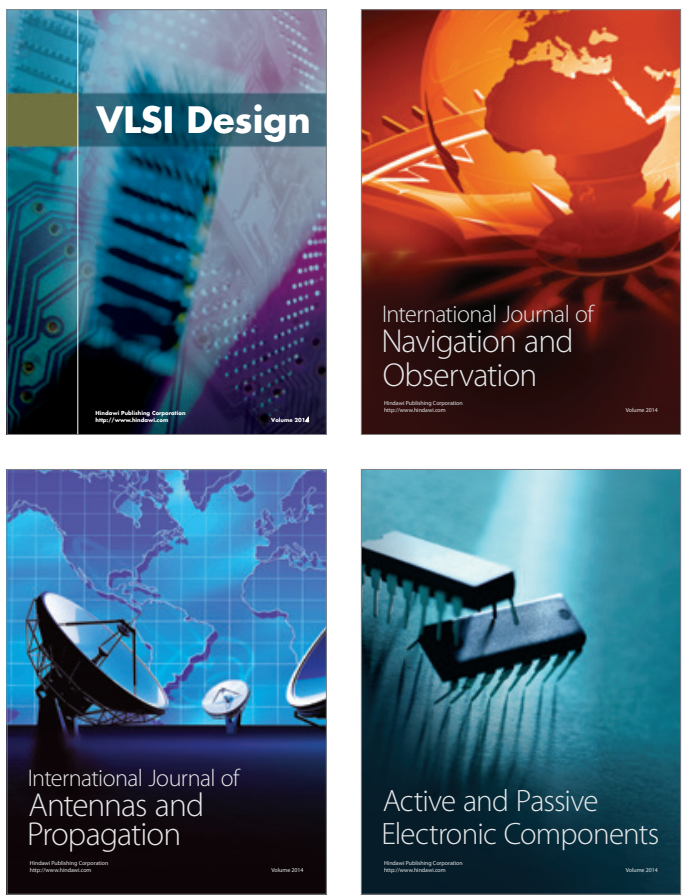


International Journal of

Distributed

Sensor Networks

$-$

Joumal of

Control Science

and Engineering
